\title{
Interpretation of MPPT Techniques in Grid Connected Solar PV Array System
}

\author{
Neha Singh \\ Mtech Scholar \\ Department of Electrical and Electronics \\ Bhopal Institute of Technology and Science \\ nsfocus555@gmail.com
}

\author{
Prof. Govind Prasad Pandiya \\ Head of Department \\ Department of Electrical and Electronics \\ Bhopal Institute of Technology and Science \\ govind1487@gmail.com
}

\begin{abstract}
Solar energy is one of the most used and readily available renewable energy sources among the other energy sources. The power generated by $P V$ systems is dependent on solar irradiance and temperature parameters. In the literature, many researchers and studies are interested in estimating true maximum efficiency point for the PV systems. Due to that fact, MPPT applications and techniques become an important issue for PV systems under both uniform and non uniform conditions. Although, PV system under uniform environment has only one maxima point on $P-V$ curve which is simple to estimate correctly by conventional MPPT techniques, it is not as simple as under non-uniform condition such as partial shading and mismatch effects. To overcome the drawbacks of the conventional MPPTs under non uniform condition, researchers has been investigated new soft computing MPPTs, PV array configurations, system architectures and topologies.
\end{abstract}

\section{INTRODUCTION}

The growing energy demand with the possibility of reduced supply of conventional fuels, proved by high petroleum prices, along with growing

concerns about polluting effects on environment, has driven researchers and their developments to alternative energy sources which are cleaner, renewable and produce less environmental impact. Among the alternative sources, solar energy is one of the most used and readily available renewable energy sources. Solar energy supplied by the sun in one hour is equal to the energy required by the human population in one year. Power generated by PV module depends upon the solar irradiation, cell temperature and load impedance. To efficiently utilize solar energy, maximum power point tracking (MPPT) technology is applied to operate PV systems at maximum power point. Various MPPT strategies are used in the literature to adjust power output of PV systems with the change of solar irradiance and temperature.

In general, there is only one maximum power point on P-V curve of a PV module where the PV module produces its maximum output power under uniform solar irradiance condition. Thus, in order to achieve maximum efficiency for PV systems, some conventional maximum power point tracking algorithms are used such as Hill - Climbing, Perturb \& Observe (P \& O), Incremental Conductance (Inc. Cond). Under non-uniform condition such as in a partially shaded condition, the P-V curve of the PV module exhibits multiple maximum power points due to the bypass diodes which are used to prevent hotspots on PV modules. Due to multiple local maxima points, the conventional MPPTs do not perform well and they cannot detect global maxima point on the $\mathrm{P}-\mathrm{V}$ curve. Without any intervention, the lost power due to non uniform effects can be significant. To overcome these drawbacks, researchers have been proposed several methods and techniques in the literature. Therefore, we study and classify used MPPT

techniques, different PV array configuration types, system architectures and circuit topologies in the literature. In this study, advantages and disadvantages of the discussed methods are summarized and a general comparison table for each subject of the used methods has been created carefully.

\subsection{Modeling a/solar panel}

The equivalent circuit of the general model which consists of a photo current, a diode, a parallel resistor expressing a leakage current, and a series resistor describing an internal resistance to the current flow, is shown in Fig. 1. The voltage-current characteristic equation of a solar cell is given as:

$$
\mathrm{I}=\mathrm{Iph}-\mathrm{Is}\left(\exp \left(\frac{\mathrm{V}+\mathrm{RsI}}{\mathrm{a}}\right)-1\right)-\frac{\mathrm{V}+\mathrm{RsI}}{\mathrm{Rsh}} \text {..(1) }
$$

$\mathrm{I}_{\mathrm{PH}}$ is a light-generated current or photocurrent, IS is the cell saturation of dark current, $\mathrm{q}(=1.6 \times 10-19 \mathrm{C})$ is the electron charge, $\mathrm{k}(=1.38 \times 10-2311 \mathrm{~K})$ is Boltzmann constant, $\mathrm{T}$ is the cell working temperature, 
A is the ideal factor, RSH is the shunt resistance, and $\mathrm{RS}$ is the series resistance.

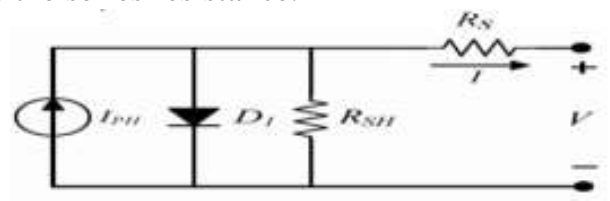

Fig.1: The equivalent circuit of a PV cell.

\subsection{DC-DC Buck-Boost Converter}

DC conversion has gained the great importance in many applications, starting from low-power applications to high power applications. In this paper, buck-boost converter is chosen to be used in the MPPT system. Buck-boost converter is used to step down and step up the DC voltage by changing the duty ratio of the MOSFET. If the duty ratio is less than 0.5 , the output voltage is less than the input voltage; while if the duty ratio is greater than 0.5 , the output voltage is greater than the input voltage. Duty ratio is the time at which the MOSFET is on to the total switching time. The buck-boost converter is shown in Figure 2. The relation between the input and the output voltages of the buck-boost converter is given as follows: [1] [2] [3].

$$
\text { Vout }=\frac{-D}{1-D} \text { Vin }
$$

On applying Kirchhoffs laws, we find the following applicable equations:

$$
\left\{\begin{array}{l}
\frac{d V_{P t^{*}}}{d t}=\frac{i_{P V^{*}}}{C_{P t^{*}}}-\frac{i}{C_{P V^{*}}} D \\
L \frac{d i}{d t}=(1-D) \cdot V+D \cdot V_{P t^{*}} \\
C \frac{d V}{d t}=-(1-D) i-\frac{V}{R}
\end{array}\right.
$$

I is the current through the inductance, the voltage across the capacitor, $\mathrm{D}$ is the duty ratio and $\mathrm{Vpv}$ is the voltage measured from the photovoltaic panel.

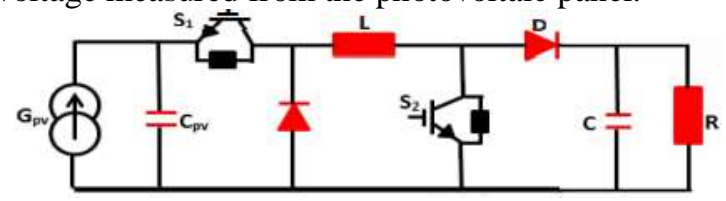

Fig.2: The buck-Boost converter circuit

\subsection{Grid-connected photovoltaic system}

Grid-connected solar PV (GCPV) systems include building integrated PV (BIPV) systems and terrestrial PV (TPV) systems. TPV systems include plants in desert, tide, and saline-alkali land. The major elements of a grid-connected solar PV system are shown in Fig. 1. Analysis of optimal photovoltaic (PV) array and inverter sizes for a grid-connected PV system in Saudin Arabia is presented in. The inverters and DCDC converters are discussed in separate sections, whereas all other components are detailed in the following subsections.

1.3.1 Solar cell Solar cell consists of a p-n junction fabricated in a thin layer of semiconductor like a p-n diode. Its operational characteristics are also same as p-n diode and depend on the solar radiations as well as surface temperature [7]. An electrical equivalent circuit of a solar cell can be represented by a single or double diode model [8]. Although the double-diode model is more accurate under certain operating conditions, the single diode equivalent model has simplicity with sufficient accuracy [9], and allows for the development of explicit models [10]. Single diode equivalent circuit with parallel and series resistances is shown in Fig. 3.

The relationship between output voltage (V) and output current (I) for the single-diode equivalent circuit of a solar cell can be described by the following relation $[11,12]$

$$
I=I_{p h}-I_{0}\left\{\exp \left[\frac{q\left(V+V R_{s}\right)}{A k T}\right]-1\right\}-\left(\frac{V+I R_{s}}{R_{s h}}\right)
$$

where Iph is the PV cell photo-current; I0 is the PV cell saturation current; $A$ is the curve fitting factor of a solar cell; Rsh is the PV cell shunt resistance; Rs is the PV cell series resistance; $\mathrm{q}$ is the electron charge $(1.602 \times 10-19 \mathrm{C})$; and $\mathrm{k}$ is the Boltzmann constant $(1.38 \times 10-23 \mathrm{~J} / \mathrm{K})$.

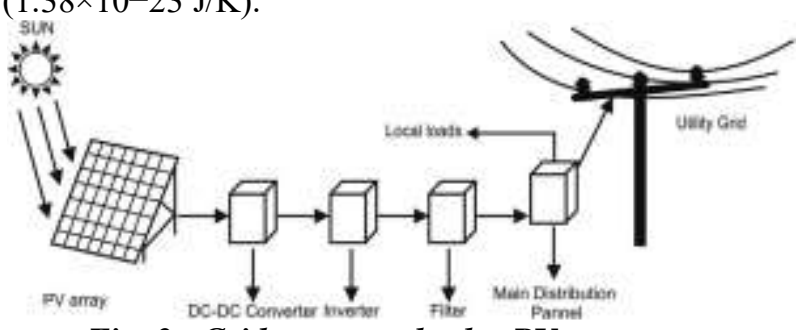

Fig. 3: Grid-connected solar PV system.

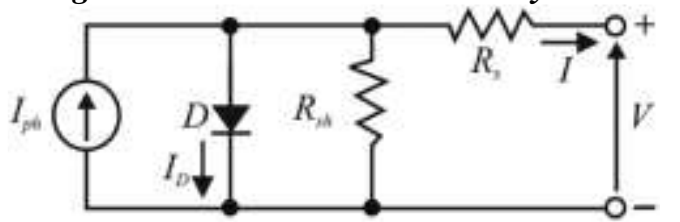

Fig.4: Single-diode equivalent circuit of a solar cell.

The output power from a single PV cell is relatively small. The required voltage and power is produced by grouping the PV cells in series and parallel forming the modules. Modules are combined to form PV panels. These panels are connected together to build up the entire PV array and any desired current-voltage characteristics could be generated $[14,15]$. Different connection topologies of solar PV array are detailed in Fig. 3. These connection topologies of solar PV arrays have been utilized in both grid-connected BIPV and 
TPV systems. However, the PV inverter topologies may differ depending on the rooftop area available for the installation of BIPV systems. The grid connected large scale BIPV systems are gaining momentum due the introduction of net-metering concept by the utilities for the electricity users.

The value of Rsh can be assumed to be infinite at short circuit conditions, where slope of the I-V characteristics is almost zero [11]. In this case, Iph is equal to the short circuit current (Isc) and Eq. (1) for solar cell reduces to the following relation conditions, where slope of the I-V characteristics is almost zero [11]. In this case, Iph is equal to the short circuit current (Isc) and Eq. (1) for solar cell reduces to the following relation [7]

$$
I=I_{s c}-I_{0}\left\{\exp \left[\frac{q\left(V+I \cdot R_{s}\right)}{A k T}\right]-1\right\}
$$

For a PV array arranged in Np parallel and Ns series connected solar cells, the Eq. (2) reduces to [13]

$$
l=N_{p} I_{s c}-N_{p} I_{0}\left\{\exp \left[\frac{q\left(V+I\left(N_{s} / N_{p}\right) R_{s}\right)}{N_{s} A k T}\right]-1\right\}
$$

An extended model of a PV module based on single exponential representation of the PV cell taking into account the ground coupling effect, leakage inductive and stray capacitive parameters is proposed in [16]. All parameters of the proposed model are characterized on the basis of experimental results obtained in real conditions. Castellano et al. [17], proposed a shading model that optimizes the minimization of distance between the rows of fixed photovoltaic panels. Proposed method is based on the exact calculation of shadows of panels for different positions of the sun. The shadow depends on the latitude of facility, throughout course of the day and for all planned hours of the solar gain. Effects of vortex shedding in arrays of long inclined flat plates and ramifications for ground mounted photovoltaic arrays is presented in [18]. Importance of cleaning concentrated photovoltaic arrays, in a desert environment, is presented by the authors in [19].

1.4 MPPT techniques PV cells and modules generate different power depended on different environment condition and electrical load. Because of that, generation of maximum power is not guaranteed at all electrical loads [6]. To extract available maximum power from PV modules or arrays, maximum power point tracking (MPPT) algorithms are used for PV systems in the literature. There are various types of MPPT techniques used to run PV modules on maximum power. In general, MPPT techniques are classified into two types.

- Conventional methods
- Soft computing methods

For conventional MPPT, the methods include perturb and observe $(\mathrm{P} \& \mathrm{O})$, incremental conductance (Inc. Cond.), hill climbing, short circuit current, open circuit voltage, ripple correlation control, current sweep control [10]. Conventional MPPT methods are efficient for uniform environmental conditions. For PV systems which work in uniform condition, there is just one maximum power point and this point changes depending on solar irradiance or temperature. Therefore, it is easy to find the maximum power point by using these conventional methods. However these techniques have continuous oscillations around MPP and this causes

loss of power. Also, conventional MPPTs are failing to track global MPP in non-uniform condition and they do not have enough ability to handle partial shading conditions. Soft computing methods such as artificial neural network, fuzzy logic control, particle swarm optimization and differential evolution have ability to find GMPP in local MPPs for non-uniform environment conditions.

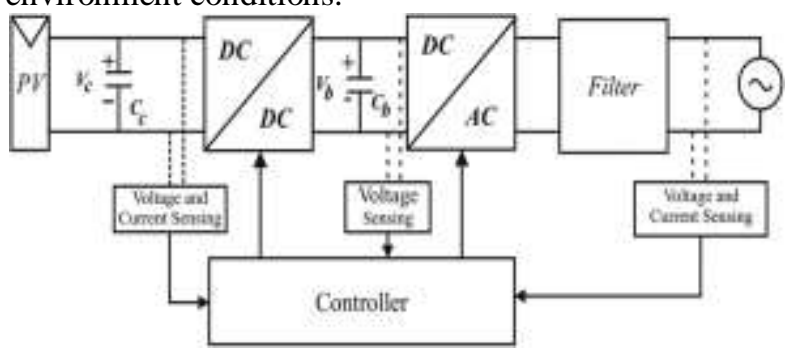

Fig.5. Block diagram of grid-connected solar PV system

1.5 DC-DC converter

A DC-DC converter is a power electronic circuit, which converts direct current of source from one voltage level to the required voltage. level. DC-DC converter is the heart of MPPT hardware for solar PV applications [4]. The operation of DC-DC converter forms the basis for the detection of MPP, according to the proposed global MPPT control algorithm [6]. Practically, the output voltage of one PV string is very low despite the use of MPPT. This requires the use of front end DC-DC converter to be equipped with a stepup capability for grid connection [5]. Arrangements of DC-DC and DC-AC converters in the block scheme of grid connected PV system are shown in Fig. 5.

\section{LITERATURE REVIEW}

[1] This research Abdullah $\mathbf{M}$ et al. presents a photovoltaic system with maximum power point tracking facility. An intelligent fuzzy logic controller method is proposed in this paper to achieve the maximum power point tracking. The system is modeled using MATLAB/SIMULINK. The system 
has been experienced under disturbance in the photovoltaic temperature and irradiation levels. The simulation results show that the proposed maximum power tracker tracks the maximum power accurately and successfully in all conditions tested.

[2] In this study, Rasoul Rahmani et al. simulation and hardware implementation of Fuzzy Logic (FL) Maximum Power Point Tracking (MPPT) used in photovoltaic system with a direct control method are presented. In this control system, no proportional or integral control loop exists and an adaptive FL controller generates the control signals. The designed and integrated system is a contribution of different aspects which includes simulation, design and programming and experimental setup. The resultant system is capable and satisfactory in terms of fastness and dynamic performance

[3] Carlos Mezaet al. describes the analysis, modeling and control of a transformer less boost-buck power inverter used as a DC-AC power conditioning stage for grid-connected photovoltaic (PV) systems. The power conditioning system's control scheme include a variable structure controller to assure output unity power factor and a sensor less maximum power point tracking (MPPT) algorithm to optimize the PV energy extraction.

[5] Hu Y, Cao W et al. proposes a new multi-stage hysteresis control of a step-up DC DC converter for integrating PVs into a single-phase power grid. The proposed circuitry and control method is experimentally validated by testing on a $600 \mathrm{~W}$ prototype converter. The developed technology has significant economic implications and could be applied to many distributed generation (DG) systems, especially for the developing countries which have a large number of small PVs connected to their singlephase distribution network. $\mathrm{z}$

[6]In this paper, Koutroulis E presents a new method to track the global MPP, which is based on controlling a dc/dc converter connected at the PV array output, such that it behaves as a constant input-power load. The proposed method has the advantage that it can be applied in either standalone or grid-connected PV systems comprising PV arrays with unknown electrical characteristics and does not require knowledge about the PV modules configuration within the PV array. The experimental results verify that the proposed global MPP method guarantees convergence to the global MPP under any partial shading conditions.

\section{CONLUSION}

The power generated by photovoltaic (PV) system depends on environment irradiance and temperature parameters. Hence, PV panels have nonlinear characteristics. In uniform condition, there is only one maxima point called maximum power point (MPP) where the PV system operates in maximum efficiency. However, in non-uniform condition such as partial shading effects, the PV system presents multiple maxima points on the correspondence $\mathrm{P}-\mathrm{V}$ curve due to bypass diodes which makes more difficult to estimate global MPP. That is why it makes maximum power point tracking (MPPT) more important for PV systems to operate in maximum efficiency. This review study provides an extensive overview about the most used solutions to reduce mismatching and partial shading losses on PV systems. The maximum power point (MPP) of PV module has been well tracked by the MPPT, and the output power of PV module has not fall in local disturbances of radiation changes.

\section{REFERENCES}

[1] Abdullah M. Noman, Khaled E. Addoweesh, and Hussein M. Mashaly,"DSPACE Real-Time Implementation of MPPTBased FLC Method",Hindawi Publishing Corporation International Journal of Photoenergy Volume 2013, Article ID 549273, II pages.

[2] Rasoul Rahmani, Mohammadmehdi Seyedmahmoudian,Saad Mekhilef and Rubiyah Yusof,"lmplementation Of Fuzzy Logic Maximum Power Point Tracking Controller For Photovoltaic System", American Journal of Applied Sciences, 10 (3): 209-218, 2013.

[3] Carlos Meza, Domingo Biel, Juan Negroni, Francesc Guinjoan,"BoostBuck Inverter Variable Structure Control for Grid-Connected Photovoltaic Systems with Sensorless MPPT", IEEE ISIE 2005, June 20-23, 2005, Dubrovnik, Croatia Gaikwad D, Chavan M, Gaikwad M.

[4] Hardware implementation of dc-dc converter for mppt in pv applications. In: Proceedings of the 2014 IEEE Global Conference on Wireless Computing and Networking (GCWCN; $2014, \quad$ p. http://dx.doi.borg/10.1109/GCWCN.2014.7030839).

[5] $\mathrm{Hu} \mathrm{Y,} \mathrm{Cao} \mathrm{W,} \mathrm{Ji} \mathrm{B,} \mathrm{Si} \mathrm{J,} \mathrm{Chen} \mathrm{X.} \mathrm{New} \mathrm{multi-stage} \mathrm{dcdc}$ converters for gridconnected photovoltaic systems. Renew Energy 2015;74(0):247-54.

[6] Koutroulis E, Blaabjerg F. A new technique for tracking the global maximum power point of pv arrays operating under partial-shading conditions. IEEE J Photovolt 2012;2(2):18490.http://dx.doi.org/10.1109/JPHOTOV.2012.2183578.

[7] Kuo C-L, Lin C-H, Yau H-T, Chen J-L. Using selfsynchronization error dynamics formulation based controller for maximum photovoltaic power tracking in microgrid systems. IEEE J Emerg Sel Top Circuits Syst 2013;3(3):45967.

[8] xian Lun S, Wang S, hong Yang G, ting Guo T. A new explicit double-diode modeling method based on lambert w-function for photovoltaic arrays. Sol Energy 2015;116(0):69-82.

[9] Uoya M, Koizumi H. A calculation method of photovoltaic array's operating point for mppt evaluation based on onedimensional newton raphson method. IEEE Trans Ind Appl 2015;51(1):567-75.

[10] Psarros G, Batzelis E, Papathanassiou S. Partial shading analysis of multistring pv arrays and derivation of simplified 


\section{IJOSTHE \\ ISSN: 2349-0772 | Volume 5 Issue 6 December 2018 |www.ijosthe.com}

mpp expressions. IEEE Trans Sustain Energy 2015;6(2):499508.

[11] Ding K, Bian X, Liu H, Peng T. A matlab-simulink-based pv module model and itsapplication under conditions of nonuniform irradiance. IEEE Trans Energy Convers 2012;27(4):864-72.

[12] Eldahab YEA, Saad NH, Zekry A. Enhancing the maximum power point tracking techniques for photovoltaic systems. Renew Sustain Energy Rev 2014;40(0):505-14.

[13] Bendib B, Belmili H, Krim F. A survey of the most used \{MPPT $\}$ methods: conventional and advanced algorithms applied for photovoltaic systems. Renew Sustain Energy Rev 2015;45(0):637-48.

[14] Koutroulis E, Blaabjerg F. A new technique for tracking the global maximum power point of pv arrays operating under partial-shading conditions. IEEE J Photovolt 2012;2(2):18490.

[15] Manna DL, Vigni VL, Sanseverino ER, Dio VD, Romano P. Reconfigurable electrical interconnection strategies for photovoltaic arrays: a review. Renew Sustain Energy Rev 2014;33(0):412-26.

[16] Spertino F, Sumaili J, Andrei H, Chicco G. Pv module parameter characterizationfrom the transient charge of an external capacitor. IEEE J Photovolt 2013;3(4):1325-33.

[17] Castellano NN, Parra JAG, Valls-Guirado J, ManzanoAgugliaro F. Optimal displacement of photovoltaic arrays rows using a novel shading model. Appln Energy 2015;144(0):1-9.

[18] Strobel K, Banks D. Effects of vortex shedding in arrays of long inclined flat plates and ramifications for ground-mounted photovoltaic arrays. J Wind Eng Ind Aerodyn 2014;133(0):146-9.

[19] Khonkar H, Alyahya A, Aljuwaied M, Halawani M, Saferan AA, Al-khaldi F, et al. Importance of cleaning concentrated photovoltaic arrays in a desert environment. Sol Energy 2014;110(0):268-75. 